\title{
POESIA CLÁSSICA CHINESA - DINASTIA TANG: APRESENTAÇÃO, ALGUNS POEMAS
}

\author{
कृen \\ RICARDO PRIMO PORTUGAL
}

Resumo: Exposição resumida dos princípios que orientaram as traduções do livro "Antologia da Poesia Chinesa - Dinastia Tang”, no prelo, contendo excertos da introdução da obra, os quais abordam aspectos estruturais da poesia clássica chinesa, desenvolvendo os conceitos de paralelismo, harmonização sonora/aliteração, tradução-recriação, tradução estrangeirizante e outros, com base em aportes teóricos de Walter Benjamin, Roman Jakobson, Haroldo de Campos, François Cheng e outros autores.

Palavras-chave: Poesia; Dinastia Tang; formas clássicas; paralelismo; harmonização sonora.

\begin{abstract}
This article is a brief presentation of the guiding principles we applied to the translation of the poems selected for inclusion in "Antologia da Poesia Chinesa - Dinastia Tang [Anthology of Chinese Poetry - Tang Dynasty]", which will soon be published. It contains excerpts from the introduction to the book, which includes commentaries on the structural aspects of classical Chinese poetry (concepts of parallelism, sound harmonization/alliteration, translation as re-creation, translation as a foreignizing strategy). The article takes into account the theoretical contributions of Walter Benjamin, Roman Jakobson, Haroldo de Campos, François Cheng and other authors.
\end{abstract}

Keywords: Poetry, Tang Dynasty; classical forms; parallelism; sound harmonization. 
$\mathrm{E}$ stá no prelo a Antologia da Poesia Chinesa - Dinastia Tang (Editora UNESP), resultado mais consistente de nossas atividades de estudo e tradução durante os últimos anos. Esse livro, que preparei em coautoria com Tan Xiao, será, muito possivelmente, a primeira coletânea mais abrangente, publicada em nossa língua, da poesia da Dinastia Tang (618-907), a “idade de ouro" da literatura chinesa clássica. Com mais de 200 poemas, a Antologia contém, além de textos dos três principais nomes da poesia clássica - Li Bai, Du Fu, Wang Wei -, também traduções de Bai Juyi, Meng Haoran, Li Shangyin, Du Mu, Liu Yuxi, Cen Shen, Wen Tingyun, Li He, Meng Jiao, Jia Dao, Han Yu, Cui Hao, e vários outros, totalizando mais de 30 autores, na maioria inéditos em português, inclusive representantes da vertente feminina da literatura chinesa - Li Ye, Xue Tao, Yu Xuanji.

Acreditamos que a edição primorosa da Editora UNESP - bilingue, com introdução histórica e de teoria literária, notas explicativas e resenhas sobre os autores, também preparadas pelos tradutores - é uma contribuição relevante para a ambiência dos estudos da literatura chinesa em países de língua portuguesa. O trabalho baseia-se, principalmente, nas antologias mais consagradas - 300 Poemas da Dinastia Tang (século XVII), e Poemas de 1000 mestres (século XIII) -, além de repassar os principais textos de referência da tradição da tradução em português, inglês, francês e espanhol. Na introdução e nas notas, também são abordadas questões da teoria da tradução, apresentam-se aspectos estruturais da poesia clássica chinesa, expondo-se os conceitos de paralelismo, harmonização sonora/aliteração, tradução-recriação, tradução estrangeirizante, com base em aportes teóricos de Walter Benjamin, Roman Jakobson, Haroldo de Campos, François Cheng, Ezra Pound, Octavio Paz e outros autores.

A seguir, expomos alguns aspectos estruturais do poema clássico chinês, conforme abordados na introdução da obra.

\section{Estrutura do poema clássico chinês}

No princípio da Dinastia Tang, as pesquisas formais e estudos linguísticos haviam chegado a um elevado grau de refinamento. Seja pelo desenvolvimento próprio da ambiência literária, seja por necessidade dos exames imperiais, que demandavam a sistematização de conteúdos, chegou-se, por essa época, a uma codificação e definição precisa das formas em uso, as quais constituirão os modelos clássicos, predominantes até o advento do Modernismo, nas primeiras décadas do século XX.

Distinguem-se o "Estilo Novo" (jintishi), com regras bem definidas e formas fixas, e o "Estilo Antigo" (gutishi), que trabalhava formas mais tradicionais e de origem popular, caracterizado pela relativa ausência de restrições ou delimitações formais. No "Estilo Novo", a forma básica, considerada o fundamento das demais, era o octeto regular, lüshi. O quarteto regular, jueju, forma em que poetas da relevância de Wang Wei, Du Mu e Meng Haoran foram particularmente exímios, era definido como um lüshi cortado, reduzido ou "suspenso". Havia também o changlü (literalmente, “lüshi alongado”), que acrescentava novos versos. 
A poesia dessa época também se beneficiou da consolidação de padrões métricos no decorrer de uma história literária já bastante longa e sem interrupções. O verso chinês no jintishi, assim como na maior parte das composições no gutishi, era de métrica fixa em cinco ou sete sílabas. No gutishi encontram-se também composições que alternam ambas as métricas, ou que as modificam com a utilização também de versos menores (sobretudo em quatro sílabas, uma importante unidade métrica da poesia mais antiga, bastante praticada nas canções do Shi Jing). Cite-se também o ci (canção), forma que tende a maior variedade métrica. Essa "poesia cantada" ou "letra de música" foi praticada pela maioria dos poetas em alguma medida e ganhou popularidade crescente ao final da Dinastia Tang, vindo a assumir um lugar central na Dinastia Song.

Quanto à métrica regular do "Estilo Novo" (jintishi), que predomina também nos demais poemas clássicos chineses, mantivemos a mesma solução que utilizamos em nossa tradução anterior, Poesia completa de Yu Xuanji (2011). Com algumas exceções, transpusemos para a língua portuguesa a métrica dos originais em cinco sílabas para decassílabos ou, em alguns casos, versos de nove sílabas. Os de sete sílabas passaram, em geral, para doze ou onze sílabas. Essa escolha não é tão arbitrária: se quantificarmos os "morfemas" nos versos chineses (isto é, as "palavras”, ou as unidades de significante-significado, naquela língua monossilábica e não flexional), chegaremos aproximadamente a uma duplicação silábica em português, língua latina flexional (de frases muito longas, quando comparadas às chinesas). Interessante o fato de que, justamente, o verso clássico português por excelência, conforme fixado desde Camões, é o decassílabo.

\section{“Estilo Novo”: análise e tradução do octeto regular (lüshi)}

O octeto lüshi é a forma que serve de referência às demais no "Estilo Novo". Sua estrutura representa uma unidade semântica e sintática complexa, na qual se verifica a consolidação de séculos de desenvolvimento da poesia e da teoria literária.

A unidade mínima do octeto é o dístico, 对联 (duilian). Ele é organizado sobre o princípio do paralelismo, que consiste em uma estrutura de dois sintagmas em relação de "espelhamento", em correspondência entre seus elementos constituintes. As classes/funções gramaticais dos versos em paralelismo se correspondem, termo a termo. Apõe-se, assim, uma leitura vertical, paradigmática, que se cruza ou complementa à leitura horizontal, sintagmática. ${ }^{1}$ Esse princípio de utilização da linguagem foi abrigado pela poesia clássica, mas está presente em usos quotidianos da língua. Sua tendência a marcar momentos discursivos "especiais" - dísticos nos portais das casas; fachadas de templos; festas; práticas religiosas e, mais simplesmente, em expressões idiomáticas e frases estereotipadas "de efeito" - parece indicar uma origem ritualística.

\footnotetext{
${ }^{1}$ Sobre as noções de eixo paradigmático e eixo sintagmático da linguagem, ver Roman Jakobson (2007).
} 
A título de exemplo de um dístico paralelo (ou organizado por paralelismo), vejamos os versos a seguir, extraídos de poema de Du Fu ("Contemplando a Grande Montanha”):

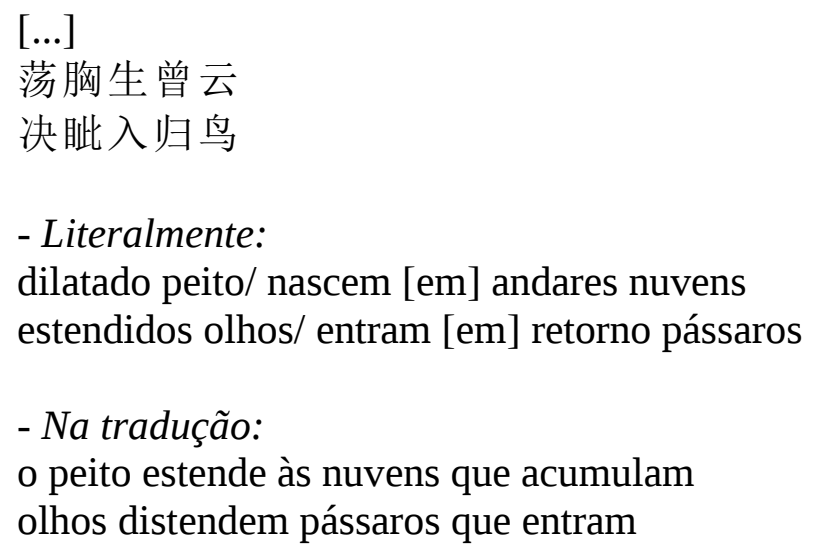

Nota-se a correspondência entre os elementos lexicais (as classes/funções de palavras) do verso superior e do inferior. Impõe-se (ou talvez: sugere-se, revelase, está subsumida) uma leitura vertical dilatado-estendido; peito-olhos; nascempenetram; em andares-em retorno; nuvens-pássaros. As palavras do dístico dispõem-se de maneira simétrica, em correspondência paradigmática, estabelecendo entre elas relações de oposição ou de complementaridade. Essa estrutura de correspondências binárias entre versos é então trabalhada, no octeto, em pares semânticos de conjunção ou disjunção. O segundo verso traz inaugurações, transformações, ou simples oposições aos elementos do primeiro.

No caso desse dístico de Du Fu, vê-se um recurso adicional de significação, propiciado pelo paralelismo, que é explorado com maestria pelo poeta (e que a tradução em português busca reproduzir em alguma medida): a inversão sintática. Isto é: os termos organizam-se simetricamente, mas sua ordem sintática foi alterada. Esse recurso é uma exploração particularmente ousada do paralelismo, em uma língua de sintaxe posicional, na qual a ordem dos termos é fundamental para sua função sintática. Esses versos causam grande estranhamento em chinês, como se significassem: "o peito dilatado produz nuvens em camadas/os olhos distendidos entram nos pássaros que voltam”.

O paralelismo é também chamado por alguns autores de "contraponto semântico” (Demiéville, 1962), metáfora da teoria musical, mas pertinente, na medida em que se trata da superposição, ou justaposição, de significações opostas ou complementares, que "soam juntas”, integram-se em um nível superior de significação, em um processo de conotação. ${ }^{2}$

Naturalmente, também a musicalidade, isto é, a harmonização fonética do poema, é um dos instrumentos da linguagem poética em que se apoia o efeito semântico do paralelismo - que, a rigor, é uma espécie de “eco semântico”, uma for-

\footnotetext{
${ }^{2}$ Ver, a propósito, a teoria da conotação como superposição de signos, conforme explicado, por exemplo, por Roland Barthes em Elementos de semiologia (1989).
} 
ma codificada de repetição. O poema clássico é sempre rico em aliterações, assonâncias, rimas, onomatopeias e recursos sonoros em geral.

O paralelismo acentua o eixo paradigmático em uma leitura que se acresce ou se cruza à do sintagma. Nesse sentido, é um recurso que estabelece interrupções ou pausas nos aspectos linear e discreto, essenciais ao signo linguístico (conforme ensinado por Saussure), alterado no uso da poesia, arte na qual o texto se amplia até a intersecção com as artes plásticas e a música. Em se tratando da poesia chinesa clássica, isso se acentua pela escrita ideogramática, a visualidade, o movimento e a musicalidade intrínsecos ao caractere chinês.

Para além do conceito geral de paralelismo, considera-se que, no plano sintático, o fato mais importante do octeto clássico chinês é a oposição entre versos paralelos e não paralelos. Assim, o primeiro dístico é, geralmente, de versos não paralelos, mas é admissível que sejam paralelos. O segundo e o terceiro dístico são obrigatoriamente construídos em paralelismo e o último é necessariamente de versos não paralelos.

Têm-se, desta forma, uma estrutura na qual o último dístico e, na maioria dos casos, também o primeiro são afeitos a uma ordem temporal, isto é: fixam uma moldura de narratividade para o poema. Os dois dísticos paralelos ao centro dispõem uma ordem espacial, em que um conjunto de signos engendra um outro, contrário ou complementar, através do qual uma instância pictorial-descritiva se impõe, em uma suspensão da progressão temporal-lógica.

Em um dístico paralelo, o primeiro verso se desdobra sem propriamente transitar para o segundo; ele se suspende, para ser confirmado, modificado ou fechado pelo segundo. A sensação que se encontra, muitas vezes, em um poema chinês clássico, é de que há sintagmas inconclusos, abertos, submetidos a fragmentações e quebras sucessivas. É o eixo paradigmático que se acentua nesses versos.

Segundo François Cheng (op. cit., tradução nossa): “de um ponto de vista linguístico, o paralelismo é uma tentativa de organização espacial dos signos no interior de seu desenvolvimento temporal”.

Observemos outros aspectos importantes da estrutura do poema clássico, que se colocam para os tradutores:

1. Métrica, esquema sonoro e visual: a poesia clássica chinesa segue esquemas sonoros complexos; além da métrica, cujos princípios gerais já expusemos acima, há estruturas padronizadas quanto a rima de final de verso (sempre a mesma rima percorre um poema, em versos alternados, em primeiro tom), padrões tonais (a língua é tonal, o que também é um recurso incorporado na poesia); esquema visual (propiciado pela visualidade dos caracteres chineses), em uma estrutura geral de intensa aliteração e assonância. Quanto à rima, procuramos soluções mais chegadas à tradição da língua portuguesa, mas optamos, talvez na maioria dos casos, pelas rimas toantes. Essa escolha é estilisticamente mais contemporânea do que, em geral, as rimas consoantes e, simultaneamente, mais assemelhada ao esquema sonoro do poema chinês clássico.

2. Aspectos semântico-lexicais - supressão das palavras vazias: na poesia clássica chinesa, sobretudo no jintishi (“Estilo Novo”), pratica-se um código de supressão das palavras vazias (conceito gramatical chinês referente a nexos, conexões, 
pronomes) e a ênfase às palavras cheias (nomes e verbos ativos). Um efeito significativo dessa regra é o deslocamento do "eu-lírico" e a instauração de uma "objetivação” da linguagem. Ainda que, no chinês, a supressão do pronome pessoal seja mais frequente que no português, mesmo na fala corrente, na poesia clássica tratase de um código estrito, utilizado de maneira especial, que instaura um ambiente linguístico “artificial”, distante do uso "natural”. Esse modelo deixou marcas na poesia de países cujas culturas foram influenciadas pela China, em especial pela Dinastia Tang - por exemplo, a objetividade do hai-cai japonês lhe é tributária. A objetivação do texto pelo deslocamento, ou não explicitação, do eu-lírico é também um recurso presente na poesia contemporânea ocidental e brasileira, o qual procuramos ter como parâmetro na maioria de nossas traduções.

\section{Traduzir-recriar poesia clássica chinesa}

Há, portanto, desafios específicos na tradução da poesia clássica chinesa colocados por características da língua e pelo alto grau de codificação das formas. Muitos recursos dessa poesia, que se apoia em uma linguagem de possibilidades simbólicas inexistentes em línguas ocidentais, são virtualmente intraduzíveis em si mesmos. Trata-se, contudo, de buscar recriar o efeito desses textos pela utilização de recursos sonoros e semânticos de nossa língua.

Sobretudo, evitar que o texto soe “normal”, facilmente assimilável como poesia de nossa cultura, o que frequentemente acaba resultando em uma diluição em favor de um modelo considerado mais ou menos "equilibrado" ou reconhecível pelo leitor médio. A tradução "fácil” é uma tentação perigosa, talvez ainda mais hoje em dia, quando um certo Modernismo simplificou e, aparentemente, "democratizou" a arte da poesia e da versificação, fixando a linguagem coloquial e o verso "livre” como princípios estruturais universais.

A sensação causada por essa espécie de tradução poderia ser bastante “estranha”, principalmente quando se trata dos textos de um mestre como Du Fu, cuja poesia é extremamente codificada, com grande virtuosismo no uso dos recursos formais. Seria o equivalente, para o leitor culto do português ou do inglês, a encontrar sonetos de Camões ou Shakespeare traduzidos para o chinês em versos livres, em transcrição literal, sem recursos sonoros, rimas e aliterações...

No caso da poesia clássica chinesa, temos formas codificadas, não "naturais”, em geral bastante dissociadas da linguagem coloquial, reproduzidas por centenas de poetas, construídas e refinadas no decorrer de uma tradição extensa. Sua tradução para o português de hoje dará em poemas modernos, mas que deverão incorporar uma leitura do classicismo chinês - o que poderá conduzir, ainda, a uma leitura comparativa do classicismo ocidental, brasileiro-português.

Buscamos uma recriação do texto chinês que seja "estrangeirizante" do texto resultante em português (ver o conceito de "foreignizing translation" exposto por Christine Froula apud Qian (2003), em “The beauties of mistranslation: on Pound's English after Cathay”. O poema estrangeiro amplia o repertório de minha língua; expande, modifica, discute o texto de minha língua; propõe uma releitura e reescrita da minha tradição, desde o exterior. O poema estrangeiro deve ser traduzi- 
do como trazendo algo novo a minha língua, para além da reiteração do conhecido. Ou, conforme a fórmula feliz de Haroldo de Campos: "tradução é a inscrição de um outro dentro do mesmo".

Assim, a tradução não será encarada como o "aportuguesamentoabrasileiramento” do poema estrangeiro, proposta que tenderia a cair na falácia de seguir uma "ficção de leitor”, como sugere Walter Benjamin (“A tarefa do tradutor”, in Escritos sobre mito e linguagem). Na descrição do filósofo alemão Rudolf Pannwitz, apud Benjamin, “(...) o erro fundamental de quem traduz é conservar o estado fortuito de sua própria língua, ao invés de deixar-se abalar violentamente pela língua estrangeira (...)” (p. 118).

Não é possível realizar uma tradução poética que recupere minimamente o original apenas com a reprodução do conteúdo, sem consciência de linguagem em relação à forma. Construído por conotação, em texto densificado pelo jogo de metáforas e metonímias, pelo trabalho artístico sobre o significante, o significado poético estará, muitas vezes, “além do texto”, dos conteúdos expressos.

Segundo o linguista Roman Jakobson (2007:72),

em poesia, as equações verbais são elevadas à categoria de princípio construtivo do texto. As categorias sintáticas e morfológicas, as raízes, os afixos, os fonemas e seus componentes [...] transmitem assim uma significação própria. A semelhança fonológica é sentida como um parentesco semântico. [...] A poesia, por definição, é intraduzível. Só é possível a transposição criativa: transposição intralingual - de uma forma poética a outra -, transposição interlingual ou, finalmente, transposição inter-semiótica - de um sistema de signos para outro, por exemplo, da arte verbal para a música, a dança, o cinema ou a pintura.

A impossibilidade da tradução apenas conteudística do texto poético fica mais evidente quando se trata de poesia chinesa, pela radical diferença de estrutura do idioma em relação à dos ocidentais. A linguagem chinesa é baseada no caractere, o sinograma, ideogrâmico e sintético. Ao contrário da língua ocidental - na qual a escrita é, sobretudo, a reprodução fonética da fala, o texto escrito chinês se realiza na síntese ideológica, cinésica (referente a movimento, no caso a dança, pela caligrafia, cf PORTUGAL, Ricardo Primo, “A dança dos caracteres chineses”...) e sonora do caractere, que pode sintetizar frases inteiras e representar contextos em uma sílaba, em acumulações de processos metafóricos.

A escrita chinesa é, em si mesma, um sistema intersemiótico, trazendo recursos poéticos desconhecidos no Ocidente. Ainda que admitindo o interesse de propostas de tradução intersemiótica, consideramos o código escrito-fonético da língua portuguesa como veículo prioritário para a tradução. Mas na medida em que a tradução trabalhe nos recursos sonoros e imagísticos da língua: se a poesia já é, por si, um texto "artificial”, distanciado do uso coloquial, tratar-se-ia de apoiar a tradução sobre a "artificialidade” ("estranhamento", conforme o conceito cunhado pelos “Formalistas Russos”) da linguagem poética, a sua alteração em relação ao uso comum diário, a partir dos recursos que nossa tradição abriga quanto às possibilidades icônicas do poema português escrito. 


\begin{abstract}
A seguir, transcrevemos alguns poemas da Antologia.
\end{abstract}

\title{
Du Fu (712 - 770)
}

\section{望岳}

岱宗夫如何

齐鲁青未了

造化钟神秀

阴阳割昏晓

荡胸生曾云

决毗入归鸟

会当凌绝顶

一览众山小

江村

清江一曲抱村流 长夏江村事事幽

自去自来堂上燕

相亲相近水中鸥

老妻画纸为棋局

稚子敲针作钓钩

多病所须唯药物

微躯此外更何求

\section{Contemplando a Grande Montanha}

E eis o Grande Tai - como dizê-lo ${ }^{3}$

além de Lu e Qi tudo é verdura ${ }^{4}$

Aqui divino e belo se concentram

se lado sul ou norte claro-escuro

O peito estende às nuvens que acumulam ${ }^{5}$

olhos distendem pássaros que entram

É preciso alcançar o extremo o cume ${ }^{6}$

de um só olhar mil picos se apequenem.

\section{A vila à beira do rio}

Um claro rio se dobra em torno à vila e corre, longo o verão - rio, vila, tudo maravilha.

Vão livremente e vêm aos pares andorinhas, chegam-se às águas, perto, ajuntam-se gaivotas.

A esposa um tabuleiro de xadrez recorta, o jovem filho dobra agulhas, faz anzóis. Alguém doente busca as plantas para a cura, humilde corpo, nada além disso procura.

3 O título é, literalmente, "contemplando Yue”. O termo Yue se aplica especialmente às cinco grandes montanhas da China: Monte Song, no centro do país (Henan); Tai, no leste (Shangdong); Hua, no oeste (Shanxi); Heng, no sul (Hunan), e o outro Heng, no norte (na fronteira de Hebei e Shanxi). O Yue deste poema é o Monte Tai, objeto de veneração desde a antiguidade. Este poema - um dos mais famosos de $\mathrm{Du} \mathrm{Fu}$ - foi escrito em 736. Então jovem, solteiro, com 24 anos, o pai vice-prefeito de uma cidade próxima ao Monte Tai, o poeta passara pela famosa montanha ao retornar para casa após ter falhado nos exames para o serviço público, em Chang'An. O poeta chama o Monte de "Daizong”, um dos nomes da divindade daquela montanha, que significa, aproximadamente, "o mais antigo (o decano, o veterano) dos montes".

${ }^{4}$ Qi e Lu eram os nomes de dois Estados independentes que, em tempos mais antigos, situavam-se a norte e a sul do Monte Tai, os quais abarcavam praticamente toda a atual Província de Shandong. Os Estados deixaram de existir, mas seus nomes continuaram sendo usados para denominar as áreas que ocupavam.

${ }^{5}$ Os versos $5^{\circ}$ e $6^{\circ}$, em chinês, trabalham inversões sintáticas, algo muito raro na poesia chinesa, mas explorado por Du Fu. O efeito é de ambiguidade e grande estranhamento. Há um deslizamento metonímico dos termos da frase, sugerindo a fusão do corpo do poeta (o peito, os olhos) com o ambiente da montanha, o que procuramos manter na tradução através da imprecisão sintática das funções nominais, da utilização ambígua das regências verbais, além da aliteração.

${ }^{6}$ Os dois últimos versos deste poema estão entre os mais famosos da literatura chinesa. 


\section{江畔独步寻花 (三)}

不是爱花即欲死 只恐花尽老相催 繁枝容易纷纷落 嫩荵商量细细开

天末怀李白

凉风起天末

君子意如何

鸿雁几时到

江湖秋水多

文章憎命达

鬼离鬼未喜人过

应共冤魂语

投诗赠泪罗

\section{BAI (701-762)}

\section{玉阶怨}

玉阶生白露 夜久侵罗袜 却下水晶帘 玲珑望秋月

越女词

镜湖水如月

耶溪女如雪

新妆荡新波

光景两奇绝

\section{Admirando as flores sozinho junto ao rio (III)}

Não é que em tanto amar as flores se faleça, mas há sofrer que cessam: envelhecer se apressa. Galhos repletos facilmente caem tensos, tenros botões combinam-se, abrem docemente.

\section{Pensando em Li Bai no além-céu}

Um vento frio ascende ao além-céu que pensamento a tua mente acede Quando este ano os gansos chegariam no outono os rios se enchem em demasia

Escritos são desdita ao vil mundano demônios gozam com o fracasso humano Deixa aos iguais o teu falar maldito joga um poema às águas deste rio

\section{Lamento da escadaria de jade}

Degraus de jade nasce o branco orvalho tardia noite a entrar nas meias seda Baixa a cortina em contas de cristais lua de outono vaza em transparências

\section{Canção da Dama do Sul}

as águas ao luar no lago-espelho na margem branca a dama à beira neve o robe abrindo-se ao bater das ondas onde cintila o brilho ali ressoa 
古风·西上莲花山

西上莲花山 迢迢见明星

素手把芙蓉

虚步蹑太清

霓裳曳广带

飘拂升天行

邀我登云台

高揖卫叔卿

恍恍与之去

驾鸿凌紫冥

俯视洛阳川

茫茫走胡兵

流血涂野草

豹狼尽冠姃

\section{WANG WEI (699-759)}

渭城曲

渭城朝雨浥轻尘

客舍青青柳色新

劝君更尽一杯酒

西出阳关无故人

\section{Canto antigo (a oeste eleva-se o Monte do Lótus...)}

a oeste eleva-se o Monte do Lótus ${ }^{7}$

ao longe Estrela assoma inteira tocha ${ }^{8}$

a flor sagrada a alva mão tomara

ao passo etéreo no Grande Vazio ${ }^{9}$

o robe em faixas abre-se arco-íris

flutua vento ao caminhar celeste

ela convida às nuvens o terraço

para saudar o imortal Wei Shuqing ${ }^{10}$

vagar vagar segui-la em seu percurso

do cisne ao dorso surge a obscura esfera

e ainda abaixo ao rio vê-se Luoyang ${ }^{11}$

bárbaros tropas fileiras sem fim

a erva selvagem em sangue regurgita

lobos chacais a sanha no comando

\section{Canção da cidade Wei}

A chuva da manhã sobre a poeira leve, no albergue ao pátio o verde intenso dos salgueiros;

então, senhor, toma outro copo deste vinho:

a oeste, além do Passo Yang, não tens amigos.

\section{A cascata dos pássaros}

quietude caem as flores da canela à noite pousam a montanha cala súbito aponta a lua - a primavera

desperta em brados pássaros cascata

\footnotetext{
${ }^{7}$ Poeta de um imaginário religioso etéreo e celestial, Li Bai tem diversas composições sobre o tema de viagens em sonhos por lugares sagrados para os taoístas, em companhia de imortais e divindades. O Pico do Lótus é o mais alto da Montanha Hua (na Província de Shanxi), sagrada para os taoístas.

${ }^{8}$ Li Bai descreve-se subindo ao Pico do Lótus, e lá encontra a deusa da Montanha 明星 (Ming Xing, "Estrela Brilhante") .

${ }^{9}$ Grande Vazio: expressão das doutrinas taoísta e budista.

${ }^{10}$ Wei Shuqing: divindade taoísta que habita o Monte Hua. Lê-se "xutchin"

${ }^{11}$ Versos 11-14: Desde sua evasão, o poeta contempla a miséria e os horrores do mundo. A referência à guerra diz respeito à rebelião de An Lushan, durante a qual deu-se a invasão de Luoyang e o massacre quase total de sua população.
} 


\section{BAI JUYI (772 - 846)}

赋得古草原送别

$$
\begin{aligned}
& \text { 离离原上草 } \\
& \text { 一岁一枯荣 } \\
& \text { 野火烧不尽 } \\
& \text { 春风吹又生 } \\
& \text { 远芳侵古道 } \\
& \text { 晴翠接荒城 } \\
& \text { 又送王孙去 } \\
& \text { 萋萋满别情 }
\end{aligned}
$$

池上

山僧对棋坐

局上竹阴清

映竹无人见

时闻下子声

\section{Despedida entre as ervas na planície antiga}

tenras ternas ervas na planície todo ano fanam-se e então crescem fogo novo queima e ainda teimam vem a primavera e ao vento vingam

longe o odor invade a antiga rua clara verde joia em velhos muros seguem o amigo ao longo da alameda medram tremem fremem em sentimento

\section{No lago}

dois monges da montanha frente a frente jogam xadrez entre os bambus a sombra entre os bambus frescor ninguém se vê por vezes ouve-se uma peça move

Ricardo Primo Portugal

ricardo.pportugal@yahoo.com

Diplomata, Embaixada do Brasil em Xangai 


\section{Referências bibliográficas}

BARTHES, Roland. Elementos de semiologia. Lisboa: Edições 70, 1989.

BENJAMIN, Walter. "A tarefa do tradutor”, in Escritos sobre mito e linguagem. São Paulo, Duas Cidades-Editora 34, 2011.

CAMPOS, Haroldo. Escrito sobre jade. Poesia clássica chinesa reimaginada. Ouro Preto, Tipografia do fundo de Ouro Preto, 1996.

. Escrito sobre jade. Poesia clássica chinesa reimaginada. Cotia, Ateliê Editorial, 2009. . O arco-íris branco. Rio de Janeiro, Imago, 1997.

CHENG, François. L'écriture poétique chinoise. Paris: Éditions du Seuil, 1996.

Demiéville, Paul. Anthologie de la poésie chinoise classique. Paris, Gallimard, 1962.

JAKOBSON, Roman. Linguística e comunicação. São Paulo, Cultrix, 2007.

PORTUGAL, Ricardo Primo. "A dança da poesia - uma semiótica do caractere chinês”. Página eletrônica: http://www.sibila.com.br/index.php/critica/1902-adanca-da-poesia-uma-semiotica-do-caractere-chines. Consulta realizada em 20 de fevereiro de 2013.

. "Poesia completa de Yu Xuanji”. (Entrevista a Ronald Augusto). Página Eletrônica: http://www.sibila.com.br/index.php/critica/1867-poesiacompleta-de-yu-xuanji. Consulta realizada em 20 de fevereiro de 2013.

QIAN, Zhaoming (Org.). Ezra Pound and China. Ann Arbor (MI), University of Michigan Press, 2003.

YIP, Wai-lin. Chinese poetry. An anthology of major modes and genres. Durham and London, Duke University Press, 1997.

Yu, Xuanji. Poesia completa de Yu Xuanji. Tradução, organização, prefácio e notas de Ricardo Primo Portugal e Tan Xiao. São Paulo, UNESP, 2011. 